\title{
Scriptorium
}

\section{Entre a finitude e a autenticidade: o ser-para-a-morte como indicativo de uma existência autêntica em "A morte de Ivan Ilitch", de Liev Tolstói}

\author{
Between the finitude and the authencity: the being-to-death as \\ manifestation of an authentic existence in "The death of Ivan \\ Ilitch", by Leo Tolstoy
}

\author{
Rafael Lucas Santos da Silva ${ }^{*}$
}

\begin{abstract}
Resumo: $O$ artigo propõe uma hipótese de leitura da narrativa "A morte de Ivan llitch" (1886), do escritor russo Liev Tolstói (1828-1910), a partir da analítica ontológica heideggeriana. Com base, especialmente, na categoria ser-para-a-morte, exposta na obra Ser e Tempo (1927), focaliza-se a trajetória problemática da biografia de Ivan Ilitch, com o objetivo de demonstrar que o discurso narrativo desta novela encontra-se sobredeterminado pelas instâncias discursivas da finitude e autenticidade, que se articulam de maneira orgânica e formam um esquema estético reflexivo sobre a consciência da finitude representar ao sujeito o enriquecimento axiológico de seu processo existencial. Diante dessa análise hermenêutico-fenomenológica, a abordagem da biografia do personagem Ivan llitch, como sujeito que morreu sem lograr uma singularidade autêntica, permitiu-nos discorrer acerca da vulnerabilidade do sentido da existência e a negação da finitude presente tanto no discurso ficcional quanto no processo histórico-social.
\end{abstract}

Palavras-chave: Literatura Russa; Finitude; Autenticidade; Ser-para-a-morte.

\begin{abstract}
The article proposes a hypothesis of reading the narrative "The Death of Ivan llitch" (1886), by the Russian writer Leo Tolstoy (1828-1910), based on the Heideggerian ontological analysis. Based mainly on the being-to-death category, exposed in the work Being and Time (1927), the problematic trajectory of Ivan Ilitch's biography is focused, with the objective of demonstrating that the narrative discourse of this novel is, overdetermined by the discursive instances of finitude and authenticity, which articulate in an organic way, and form a reflexive aesthetic scheme on the consciousness of finitude representing to the subject the axiological enrichment of its existential process. In view of this hermeneutic-phenomenological analysis, Ivan Ilitch's biographical approach, as subject that died without achieving an authentic singularity, allowed us to talk about the vulnerability of the meaning of existence and the denial of finitude present in both fictional discourse and the historical-social process.
\end{abstract}

Keywords: Russian Literature; Finitude; Authenticity; Being-to-death.

\footnotetext{
1 *Mestrando na área de Estudos Literários, na Linha de Pesquisa Literatura e Historicidade, pelo Programa de Pós-Graduação em Letras da Universidade Estadual de Maringá - UEM. Possui Graduação em Letras Português/Espanhol e Respectivas Literaturas na Universidade Estadual do Oeste do Paraná - UNIOESTE, campus de Foz do Iguaçu (Av. Tarquínio Joslin dos Santos, 1300 - Lot. Universitario das Americas, Foz do Iguaçu - PR) . E-mail: i3rafael@hotmail.com. Perfil orclD: https://orcid.org/0000-0002-1245-8284
} 


\section{Considerações preliminares}

A inexorabilidade do declínio biológico e da mortalidade é reconhecida com asco, como um fardo insuportável, realmente esmagador, de modo que, em nossa cultura contemporânea, busca-se a todo custo interditá-la. O historiador Ariès (2012) assinalou, nesse aspecto, que a partir do final do século XIX a morte se tornou inominável, de tal modo que "tudo se passa como se nem eu nem os que me são caros não fôssemos mais mortais" (ARIĖS, 2012, p. 100). A conclusão historiográfica é que "o afastamento da morte do discurso e dos meios familiares de comunicação pertenceria, como a prioridade do bem-estar e do consumo, ao modelo das sociedades industriais" (ARIĖS, 2012, p. 163).

A compreensão dessa transição é, pois, fundamental, uma vez que o processo histórico-social afeta diretamente a produção cultural. Ou seja, a estética literária possui ligações formativas com o processo histórico-social no qual está inserida, permitindo-nos consequentemente verificar como as narrativas ficcionais dramatizam esse período que corresponde à emergência da morte como tabu.

Obviamente, o temário da morte e mortalidade é antigo no âmbito da literatura ocidental, estando presente desde os épicos homéricos. No entanto, a partir da lição dialética legada por Candido (2006), sabe-se que a estrutura estética das narrativas ficcionais está intimamente relacionada com o contexto histórico-social, de modo que, "justamente pelo fato de manter relações com a realidade social, a literatura incorpora as suas contradições à estrutura do significado das obras" (CANDIDO, 2006, p. 202).

Com isso, acreditamos que a novela $A$ morte de Ivan Ilitch incorporou os impasses de uma cultura na qual os sujeitos negam a própria finitude. Tolstói a publicou em 1886, em plena emergência do dilaceramento de condutas e expectativas sociais menos temerosas da fragilidade biológica do ser humano, "entre a complacência para com a morte na primeira metade do século XIX e o atual interdito da morte" (ARIÈS, 2012, p. 259).

Como é, então, tratada a temática da negação da finitude ao longo da perspectivação dos acon- tecimentos diegéticos da novela $A$ morte de Ivan Ilitch? Preocupamo-nos, assim, com a veemência ontológica desta narrativa, de modo que buscamos pautar a resposta desta questão a partir de uma leitura hermenêutico-fenomenológica, segundo a qual "interpretar é explicitar o tipo de ser-no-mundo manifestado diante do texto" (RICOUER, 1990, p. 56). Isto consiste em escrutinizar os modos de ser do personagem Ivan llitch, explicitando suas condutas e expectativas "em cada modo de ser que lhe é próprio e portanto também no entendimento-de-ser que lhe é próprio" (HEIDEGGER, 2005a, p. 67).

Tal dinâmica delineia o ser-no-mundo de Ivan llitch como "maneira de ser" [Seinsweisen] e "maneiras de agir" [Handlunguweisen], os quais abordamos e compreendemos a partir da analítica ontológica heideggeriana. A biografia de Ivan llitch, tal como exposta pelo discurso narrativo, revela apenas a preocupação de galgar prestígio socioeconômico, fazendo o que fosse necessário, sem usar de críticas à programação ditada pela sua cultura e negando, consequentemente, uma modalidade autentica de existência. No plano discursivo, essa negação de ser si-próprio está intimamente relacionada com a negação da finitude, de modo que finitude e autenticidade são duas instâncias discursivas que se articulam organicamente, formando um esquema estético muito próximo do pensamento de Heidegger (2005a, 2005b) acerca do Dasein como ser-para-a-morte e o dever do sujeito de assumir para si essa finitude como um enriquecimento ontológico.

\section{Existência, finitude e modos de ser-no-mundo a partir da analítica ontológica heideggeriana}

A publicação do tratado Ser e Tempo [Sein und Zeit], em 1927, é o resultado de um empreendimento filosófico a partir do qual Heidegger (1889-1976) objetivou evidenciar como a tradição metafísica da filosofia ocidental foi incapaz de oferecer uma caracterização ontológica positiva da perspectiva existencial do ser humano. No enquadramento hermenêutico do 
tratado havia, pois, o interesse pelo esquecimento da questão do sentido do ser provocado pelas ontologias hegemônicas vigentes na filosofia antiga e moderna; e a partir desse interesse, estabelece, ao contrário, "a questão do ser como uma questão privilegiada" (HEIDEGGER, 2005a, p. 30, grifo do autor), o que implicava "a tarefa de uma destruição da história da ontologia" (HEIDEGGER, 2005a, p. 47).

Essa tarefa de destruição do pensamento metafísico possibilitou a reposição da perspectiva existencial em um âmbito original, ao considerar o ser humano como um ente portador de uma relação fundamental ao ser, e fez da analítica ontológica elaborada por Heidegger "um modo de chegar às estruturas elementares originárias que suportam a existência humana, com todas as suas disposições, faculdades e funções" (GIACÓIA JR., 2013, p. 16, grifos do autor).

A existência humana é, dessa maneira, o fio condutor para desvelar as estruturas elementares dos modos de ser do Dasein, o qual constitui um constructo que visa superar o modo substancialista das investigações de antropologia filosófica, a fim de assinalar que a existência humana "não tem, nem nunca pode ter o modo de ser dos entes simplesmentes dados no mundo" (HEIDEGGER, 2005a, p. 79). Uma vez que o primado ôntico do Dasein reside no seu caráter ontológico, a compreensão do ser desenvolve-se através de uma analítica ontológica do Dasein nos seus diferentes modos de ser. Em suma, compreende-se que

[...] o Dasein é um ente que, na compreensão de seu ser, com ele se relaciona e comporta. Com isso, indica-se o conceito formal de existência. O Dasein existe. Ademais, o Dasein é o ente que sempre eu mesmo sou. Ser sempre meu pertence à existência do Dasein como condição que possibilita propriedade [autenticidade] e impropriedade [inautenticidade]. O Dasein existe sempre num destes modos, mesmo numa indiferença para com eles. Estas determinações do ser do Dasein, todavia, devem agora ser vistas e compreendidas a priori, com base na constituição ontológica que designamos de ser-no-mundo (HEIDEGGER, 2005a, p. 90).

Esse é um dos aspectos radicais do empreendimento filosófico de Heidegger (2005a), uma vez que, na história da filosofia ocidental, o Ser sempre foi pensado apenas em relação aos entes e, assim, nunca foi levado em conta as diferentes modalidades em que os entes existem e se mostram (GIACÓIA JR., 2013). Desse modo, a constituição fundamental do Dasein é denominada ser-no-mundo [In-der-Welt-sein], no sentido em que a facticidade cotidiana da vida é tematizada como objeto da analítica ontológica, dado que o ser humano está-no-mundo, fazendo desse mundo o projeto de suas ações e de suas possíveis condutas, pois "tal assumir relações ao mundo só é possível porque o Dasein, como ser-no-mundo, é como ele é [...]" (HEIDEGGER, 2005a, p. 94).

É somente na relação com os entes intramundanos que o Dasein pode compreender o próprio ser, visto que

[...] ser-no-mundo é, antes de tudo abertura (Erschlossenheit), estar aberto para a mundanidade (Weltlichkeit), nos planos da relação cognitiva, tecnocientífica, é lidar com as coisas, manter um relacionamento com elas enquanto utensílios (Zuhandenheit) ou, enfim, relacionar-se com os outros como pessoas, em um modo de ser-com, de compartilhar (Mit-sein) (GIACÓIA JR., 2013, p. 74).

Dessa maneira, o ser humano como Dasein, se constitui como ser-no-mundo, aberto para significações, dentro de uma existência contingente, temporal, mundana e finita. Conforme esclarece Giacóia Jr. (2013), é no mundo que o Dasein pode ser como um si-próprio ou não ser como um si-próprio, permanecendo na inautenticidade. Ou seja, o comportamento ontológico do Dasein, na facticidade cotidiana da vida, se alicerça em dois modos de ser: "o existir autêntico, como ser si-próprio (das Selbst), e a existência inautêntica: o impessoal (das Man, 'a gente')" (GIACÓIA JR., 2013, p. 74). 
Autenticidade [Eigentlichkeit] e inautenticidade [Uneigentlichkeit] são, por conseguinte, duas possibilidades "ônticas" do ser-no-mundo do Dasein, que o constitui como poder-ser a partir das relações da facticidade cotidiana, de modo que

[...] o si-mesmo do Dasein cotidiano é o si-impessoal [inautêntico], que nós diferenciamos do si-mesmo próprio [autêntico], isto é, do si-mesmo apreendido autenticamente. Enquanto si-impessoal, cada Dasein está disperso no impessoal e tem, primeiramente, de se encontrar. [...] Se o Dasein está familiarizado consigo mesmo enquanto si-impessoal, então isso também significa que o impessoal prelinea a interpretação mais próxima do mundo e do ser-no-mundo [...] (HEIDEGGER, 2005a, p. 182).

Isto significa que o Dasein, lançado no mundo com suas regras e expectativas de conduta, surge inautêntico, permanecendo assim no maior tempo de sua vida, conforme Heidegger (2005a). A existência é poder-ser, porém, na autenticidade o Dasein limita a abertura de enriquecimento axiológico de sua vida. Mesmo assim, o Dasein se afugenta na inautenticidade para furtar-se da consciência de sua finitude ontológica.

Essa fuga consiste, por sua vez, na apreensão inautêntica da morte pelo Dasein, embora, na realidade, ocorra a totalização do Dasein no ser-para-a-morte [Sein-zum-Tode]. Em outras palavras, "a condição de ser-para-a-morte é o chamado do Dasein para a sua mais radical autenticidade" (GIACÓIA JR., 2013, p. 82). Isso ocorre porque a existência é o próprio limite, de modo que a finitude perpassa a própria estrutura do Dasein, reforçando a historicidade da existência, na medida em que "somente compreendo a possibilidade da morte como possibilidade da existência e somente assumindo essa possibilidade com decisão antecipadora é que o ser humano encontra o seu ser autêntico" (REALE, 1991, p. 587).

É possível perceber, dessa maneira, que no tratado Ser e Tempo há uma relação fundamental entre finitude e a autenticidade, a partir da qual nos debru- çaremos agora na narrativa da novela A morte de Ivan llitch, explicitando como a biografia do personagem Ivan é um decaimento no mundo inautêntico da esfera burocrática, que o impele a se afugentar da consciência da finitude constitutiva do seu ser.

\section{Existência inautêntica e imprópria configuram a nulidade de todo o projeto existencial de Ivan Ilitch}

Liev Nikolaiévitch Tolstói (1828-1910) dedicou-se artisticamente ao longo de cinco décadas de produção literária, que representa uma grandiosa tentativa de discutir o sentido da existência a partir de uma visão problematizadora das relações sociais. Conforme o historiador literário Hauser (1998), isso se deve porque a moderna literatura russa surge com o propósito de significar "crítica social" (HAUSER, 1998, p. 864), de modo que é possível depreender, do conjunto da obra literária de Tolstói, "um observador incorruptível da realidade social" (HAUSER, 1998, p. 869).

O romance russo do século XIX foi cifrado em estética realista, sendo que especificamente Tolstói representa o "triunfo do realismo" (HAUSER, 1998, p. 884). Converge nesse aspecto a concepção de Lukács (1965), segundo a qual "o passo adiante que a obra de Tolstói representa na literatura mundial consiste em um desenvolvimento do grande realismo" (LUKÁCS, 1965, p. 167, tradução nossa). Dessa maneira, o teórico húngaro sustenta o argumento de que

[...] Tolstói continua a construir a tradição de Fielding e Defoe, de Balzac e Stendhal, em um período, contudo, no qual o florescimento do realismo na Europa há muito cessou e em toda a Europa se tornaram dominantes tendências que destruíam o grande realismo. Com sua produção literária, Tolstói, consequentemente, persistia na contracorrente [...]. Objetivamente o princípio do realismo de Tolstói significa a continuação do grande realismo, mas subjetivamente brota espontaneamente dos problemas artísticos e sociais de seu tempo (LUKÁCS, 1965, p. 167-168, tradução nossa). 
Temos assim, com as considerações de Hauser (1998) e Lukács (1965), o preito de um escritor que nos permite compreender, por meio de sua obra ficcional, a dinâmica da história social, com suas contradições. Sendo assim, no que se refere especificamente à novela A morte de Ivan Ilitch, observa-se a crítica ao caráter desumanizado e desumanizante das relações sociais, resultante da negação da finitude e dos processos de alienação na organização burocrática.

O quadro burocrático russo estava sob uma direção autocrática, que beneficiava a ascensão à nobreza através de serviços prestados no aparato do Estado, possibilitando um imenso crescimento de burocratas durante o século XIX cuja "regra geral em vigor no serviço público aliava a incompetência administrativa a uma profunda insensibilidade às necessidades sociais" (BRYAN, 2015, p. 148).

Esse é o contexto histórico-social no qual estão ancorados o ambiente social representado e a perspectivação dos acontecimentos diegéticos da novela $A$ morte de Ivan Ilitch. O protagonista é funcionário público, um procurador do Tribunal de Justiça em Moscou, e todo o círculo social que frequenta e se relaciona é composto por funcionários públicos. Tendo isso em vista, compreende-se então a facticidade da existência de Ivan Ilitch, no sentido em que Heidegger (2005a) considera o ser humano como um ente lançado no mundo dado que a vida se caracteriza por encontrar-se em contextos situacionais. O filósofo alemão esclarece que

[...] o estar-lançado não só não é um "feito pronto" como também não é um fato acabado. Pertence à facticidade do Dasein ter de permanecer em lance enquanto for o que é e, ao mesmo tempo, de estar envolta no turbilhão do impessoal [inautêntico]. Pertence ao Dasein que, sendo, está em jogo o seu próprio ser, o estar-lançado no qual a facticidade se deixa e faz ver fortemente (HEIDEGGER, 2005a, p. 244).

Assim, Ivan llitch, enquanto Dasein, foi lançado no contexto da obsessão pelo cargo burocrático e as convenções sociais dessa classe. Ivan é filho de
Ilya Yefimovich Golovin, que é "membro totalmente supérfluo de uma das tantas instituições também supérfluas" (TOLSTÓI, 2007, p. 19). O narrador expõe ainda, ao mencionar a carreira do pai de Ivan, que existem ministérios e departamentos burocráticos que empregam indivíduos "que não possuem o menor talento para qualquer tarefa útil” (TOLSTÓI, 2007, p. 19). Esse constitui o contexto situacional em que Ivan llitch foi lançado, sendo importante compreendê-lo por que existir no mundo da autenticidade é um tornar-se, já que o Dasein "advêm na linha temporal de um passado histórico que o precede, como membro de uma família e sociedade" (GIACÓIA JR., 2013, p. 79).

Composta por doze capítulos, a novela de Tolstói (2007) expõe ferozmente esse contexto de inautenticidade desde o primeiro capítulo. Trata-se de uma narrativa que se marca por um princípio in ultima res, ou seja, o discurso narrativo se inicia com a apresentação da reação dos colegas de trabalho de Ivan ao lerem no jornal a notícia sobre sua morte. Como assinalou Bezerra (2010), isso consiste em um dado bastante relevante, pois essa descoberta pelo jornal "traduz com perfeição o sistema de relações afetivas e sociais que impera na repartição pública" (BEZERRA, 2010, p. 137).

Mesmo o narrador pontuando que "Ivan Ilitch havia sido colega deles e era muito querido por todos" (TOLSTÓI, 2007, p. 6), duas foram as reações de seus companheiros: "ao ouvirem a notícia da morte de Ivan llitch, a primeira coisa que lhes passou pela cabeça foi o possível efeito na rodada de transferências e promoções" (TOLSTÓI, 2007, p. 6) e, em seguida, o sentimento de enfado ao lembrarem "que agora teriam de cumprir todos aqueles cansativos rituais [...] assistindo ao funeral e fazendo uma visita de condolências para a viúva" (TOLSTÓI, 2007, p. 7). Aqui, nesse momento, a morte estava interditada, seus colegas nem mesmo ousaram nomeá-la, negando-a como condição constitutiva do ser, "como se a morte fosse uma fatalidade à qual somente Ivan Ilitch estivesse sujeito" (TOLSTÓI, 2007, p. 16). De fato, Heidegger (2005b, p. 19) assevera que, "em sentido genuíno, não fazemos a experiência da morte dos outros. No máximo, estamos apenas 'junto'”. 
Dessa maneira, todos os acontecimentos decorrentes da morte de Ivan exprimem tão visceralmente a solidão do sujeito moderno, bem como o caráter desumanizante das relações sociais, em que "a morte de um burocrata é mero deslocamento de uma peça no mórbido xadrez da burocracia" (BEZERRA, 2010, p. 138).

Após a descrição de como sucede a recepção da notícia pelos seus amigos e os preparativos de seu funeral, organizado pela então viúva Praskovya Fiodorovna, os onze capítulos seguintes focalizam a biografia de Ivan, desde sua origem familiar até o seu último suspiro. A trajetória biográfica do personagem Ivan llitch é fundamental para a constituição e desenvolvimento do conflito dramático da novela e cuja descrição gravita sincronicamente em volta do inesperado processo de adoecimento, que acarretará o seu falecimento.

Não é difícil perceber que, na perspectivação dos acontecimentos diegéticos que delineia a historicidade da biografia de Ivan llitch, a necessidade do enquadramento "nas aparências exigidas pelo senso comum" (TOLSTÓI, 2007, p. 29) e nas "conveniências sociais" (TOLSTÓI, 2007, p. 31) possui um papel fundamental em sua configuração psicológica. Em nível estrutural, a descrição da biografia de Ivan feita pelo narrador é quase que exatamente uma recapitulação do retrato filosófico do Dasein que esboçamos na segunda seção deste artigo.

Durante a sua vida, Ivan busca modos de ser-no-mundo que seguem o modelo de condutas automáticas, característicos do fenômeno do impessoal, que para Heidegger (2005a) implica a "fuga diante de si e esquecimento de si" (HEIDEGGER, 2005a, p. 79). Compreende-se tal aspecto pelo fato de que Ivan possuía a "característica de sentir-se sempre atraído por pessoas que estivessem em posições mais altas que a sua. Adotava os modos e pontos de vista delas e logo estabelecia relações de amizade com essas pessoas" (TOLSTÓI, 2007, p. 21). Ivan já está enredado desde a juventude nas convenções sociais, pois "o impessoal prescreve o modo de ser da cotidianidade" (HEIDEGGER, 2005a, p. 179).

Desse modo, a prescrição impessoal afasta Ivan de percepções e experiências mais amplas de ser-no-mundo, provocando que a escolha própria de seu projeto existencial seja "silenciosamente esmagada. Tudo que é originário se vê, da noite para o dia, nivelado como algo há muito conhecido. O que se conquista com muita luta torna-se banal [...] desentranha também uma tendência essencial do Dasein, que chamaremos de nivelamento de todas as possibilidades de ser (HEIDEGGER, 2005a, p. 180, grifo nosso).

É, assim, de modo nivelado que Ivan estabelece suas maneiras de ser e agir, para ser bem quisto socialmente e alcançar promoções na carreira de magistrado. Quando alcança um cargo que Ihe proporciona uma renda confortável, começa a considerar em se casar com Praskovya Fiodorovna Mikhel. O narrador enfatiza o fato de que Ivan aspirou pelo casamento "sobretudo [por] dois aspectos: o casamento Ihe traria satisfação pessoal ao mesmo tempo em que estaria fazendo o que era considerado correto pelas classes mais altas" (TOLSTÓI, 2007, p.27).

O encantamento e a satisfação que Ivan considerou lograr com o casamento ruiu em ilusão antes que completasse dois anos. Essa decepção o fez dedicar-se na "construção de um muro que o isolasse da vida familiar" (TOLSTÓI, 2007, p. 29), de tal forma que "Ivan llitch ia transferindo o centro de gravidade de sua existência da família para o trabalho" (TOLSTÓI, 2007, p. 29).

Isso ocorre sem que seja efetuado nenhum exame metódico das expectativas sociais da classe burocrata que estava nivelando sua conduta. As promoções que adquiria the satisfazia, fazendo-o dedicar-se ainda mais à carreira, de tal modo que "todo o seu interesse concentrava-se agora no mundo de suas obrigações profissionais e estas o absorviam totalmente" (TOLSTÓI, 2007, p. 31). Sobre esse aspecto, Bezerra (2010) sintetizou que à medida que Ivan galga os cargos burocráticos, "vai assimilando a alma da burocracia e perdendo a pouca seiva de vida que ainda Ihe rega a alma original, diluindo-se no formalismo vazio e desumano do meio jurídico e esterilizando sua pouca afetividade" (BEZERRA, 2010, p. 141).

Assim as relações sociais inautênticas provocam o decaimento de Ivan, que nem percebe a sua alienação, pois "a vida continuava a correr como ele achava que tinha de ser - agradável e dentro das conveniências sociais" (TOLSTÓI, 2007, p. 31). Ivan não observa ne- 
nhuma gravidade nisso devido ao seu ser já estar sob o jugo do primado do impessoal. Conforme esclarece Heidegger (2005a), no nivelamento provocado pelo modo de ser inautêntico, o Dasein "se atém de fato à medianidade do que é conveniente, dado que se admite como valor ou desvalor, do que concede ou nega sucesso" (HEIDEGGER, 2005a, 179-180).

Essa medianidade e nivelamento é melhor observado quando Ivan e a família se mudam para Moscou. Após dezessete anos de casado, surge excelente proposta de promoção em sua carreira que deixa toda a família feliz. Em Moscou, Ivan compra "um charmoso apartamento, o tipo de coisa com que o casal sempre sonhara" (TOLSTÓI, 2007, p. 36). O próprio Ivan decorou-o, com a finalidade de torná-lo com um "aspecto refinado e elegante, sem um toque de vulgaridade" (TOLSTÓI, 2007, p. 37). No entanto, o narrador expõe o quanto a decoração apenas enquadrava-se nas aparências exigidas pelo senso comum:

$\mathrm{Na}$ realidade, o efeito não passava do que normalmente é visto nas casas de pessoas que não são exatamente ricas, mas que querem parecer ricas e o máximo que conseguem é parecer-se com todas as outras pessoas de sua classe: havia damascos, ébano, plantas, tapetes, enfeites de bronze, tudo muito sóbrio e bem polido, tudo aquilo que as pessoas de uma determinada classe social possuem para parecerem outras pessoas. $E$ no caso dele o efeito era tão exato que não causava impressão alguma [...] (TOLSTÓI, 2007, p. 38).

Do ponto de vista da analítica ontológica, percebe-se aqui o nivelamento das possibilidades de ser-no-mundo, pelo fato de Ivan sustentar o seu projeto de existência no modo inautêntico [das Man], que para Heidegger (2005b) torna-se até uma ditadura:

O impessoal desenvolve a sua própria ditadura nesta falta de surpresa e de possibilidade de constatação. Assim nos divertimos e entretemos como impessoalmente se faz; lemos, vemos e julgamos sobre literatura e arte como impessoalmente se vê e se julga [...]. O impessoal pode, por assim dizer, permitir-se que se apoie impessoalmente nele. Pode assumir tudo com a maior facilidade e responder por tudo, já que não há ninguém que precise responsabilizar-se por alguma coisa. O impessoal sempre "foi" quem... e, no entanto, pode-se dizer que não foi "ninguém". Na cotidianidade do Dasein, a maioria das coisas é feita por alguém de quem deve dizer que não é ninguém (HEIDEGGER, 2005b, p. 40).

Sendo assim, as maneiras de ser e agir de Ivan llitch são tão previsíveis dentro da classe que ele pertence que pode-se dizer que não é ninguém, afoga-se na massificação da impessoalidade; por isso que na facticidade cotidiana se entrega a um esquecimento cego, em cujos afazeres "fazia-se necessário excluir dali tudo o que contivesse vida dentro de si - o que sempre perturba o andamento normal das coisas oficiais" (TOLSTÓI, 2007, p. 40).

Nessa ditadura do impessoal, na qual impera o modo de ser inautêntico, "o maior prazer de Ivan llitch era dar pequenos jantares, para os quais convidava pessoas de boa posição social e, assim como sua sala de visitas parecia-se com todas as outras, também suas agradáveis festinhas nada tinham de originais" (TOLSTÓI, 2007, p. 42). Acreditamos que essas passagens evidenciam claramente que o Dasein de Ivan é o ser-uns-com-os-outros, de modo que o seu Dasein, na realidade, não é ele mesmo:

[...] na medida em que o Dasein é esse entre que sou eu, mas que, simultaneamente, é, quase sempre e normalmente, determinado como ser-uns-com-os-outros, o meu Dasein não sou eu mesmo. O que ele é e como é, ninguém o é: ninguém e, contudo toda a gente em comum, toda a gente não é ela mesma. Este ninguém, que nos vive a nós mesmos na cotidianidade, é o "se" impessoal. [...] No teimoso domínio deste "se" impessoal residem as possibilidades do meu Dasein e é a partir deste nivelamento que o "eu sou" é possível. 
O ente, que é a possibilidade do "eu sou", é enquanto tal, quase sempre, um ente que é o "se" impessoal" (HEIDEGGER, 2008, p. 39).

\subsection{Angústia e compreensão da}

\section{finitude. $O$ ser-para-a-morte como elemento fundante na constituição do ser-no-mundo}

Ivan seguiu vivendo dessa forma sem nunca pensar na finitude de seu ser. Aconteceu, porém, o seu adoecimento, em consequência de uma queda enquanto ainda decorava o seu apartamento. Mesmo se consultando com especialistas renomados, Ivan nunca recebeu um diagnóstico preciso pelo o que estava passando e, assim,

A dor no lado preocupava-o e parecia ficar mais forte e mais frequente, enquanto que o gosto em sua boca era cada vez mais estranho. Tinha a sensação de estar sempre com mau hálito e seu apetite e sua força diminuíam gradativamente. Não podia mais se iludir, alguma coisa terrível, nova e importante, mais importante do que tudo o que já acontecera em sua vida, estava se passando dentro dele, alguma coisa da qual só ele estava a par. As pessoas em volta dele não entendiam, recusavam-se a entender e acreditavam que tudo no mundo continuava igual. Essa ideia atormentava-o mais do que qualquer outra coisa. Via que todos os que o rodeavam, especialmente sua esposa e filha, tão absorvidas por compromissos sociais, não só não tinham um pingo de compreensão, como ainda se irritavam com ele por andar tão deprimido e exigente, como se a culpa fosse sua (TOLSTÓI, 2007, p. 52).

No entanto, Ivan ainda não pensava na possibilidade de morrer; porque o cotidiano inautêntico de Ivan faz que seu Dasein também apreenda a morte no sentido impessoal, afinal, como assinala Heidegger (2005b), o impessoal também assegura uma interpretação para a mortalidade, a partir do discurso de que "algum dia, por fim, também se morre mas, de imediato, não é atingido pela morte" (HEIDEGGER, 2005b, p. 35).

Do contrário, Heidegger (2008) argumenta que a morte faz parte da historicidade do Dasein, de modo que "[...] o Dasein tem em si mesmo a possibilidade de se deparar com a sua morte enquanto mais extrema das possibilidades de si mesmo. Esta possibilidade extrema de ser é uma certeza, com o caráter de iminência, mas esta certeza, pelo seu lado, caracteriza-se por uma indeterminalidade total" (HEIDEGGER, 2008, p. 45).

Embora seja uma certeza, Ivan busca de toda a maneira negar esta possibilidade, esforçando-se em "voltar a antigos pensamentos que no passado o haviam protegido contra a ideia da morte" (TOLSTÓI, 2007, p. 64). Não querer reconhecer a finitude do Dasein é querer adiar perpetuamente decisões importantes sobre o próprio ser, já que o exercício inautêntico do cotidiano alivia o Dasein das responsabilidades individuais de conduzir a própria vida. Tal aspecto é nítido no modo de ser-no-mundo de Ivan, mesmo estando bastante doente:

Ivan llitch passava agora a maior parte do seu tempo nessas tentativas de reencontrar a antiga proteção mental que mantinha a morte fora de sua vista. E afastando todas as dúvidas, ia para o Tribunal, começava a conversar com seus colegas e sentava em sua cadeira com ar distraído, como era de hábito. [...] Mas, abruptamente, no meio disso tudo, a dor no lado, não importando a etapa do trabalho em que se encontrasse, surgia e impunha-se. Ivan Ilitch, assim que tomava consciência dela, tentava desviar o pensamento, mas ela resistia, teimosa. A dor chegava e postava-se frente a ele, olhando-o, afrontando-o, e ele enrijecia de pavor, a visão escurecia e perguntava-se se ela, a dor, existia realmente. E seus colegas e subordinados notavam com surpresa e 
pesar que ele, o juiz brilhante e arguto, estava se confundindo e cometendo erros. Tentava se recompor e recuperar o controle e conseguia, de alguma forma, encerrar a sessão, e voltava para casa com a triste certeza de que o trabalho já não podia, como antigamente, esconder dele o que queria que ficasse escondido e que suas atividades não podiam, definitivamente, livrá-lo dela! E pior do que tudo, ela chamava constantemente sua atenção, não para fazê-lo tomar alguma providência, mas simplesmente para fazê-lo olhar direto no seu rosto e, sem poder fazer nada, sofrer, sofrer indescritivelmente. Ele então ia para seus aposentos, deitava-se e outra vez ficava a sós com ela. Cara a cara com ela. E não havia nada que ele pudesse fazer com ela, a não ser olhar e estremecer (TOLSTÓI, 2007, p. 64,65,67).

Essa maneira de ser e agir é gritante de tudo o que até agora argumentamos. Nessa descrição do narrador, portanto, é importante notar, conforme assinalou Ariès (2012), que os indivíduos vivem como se fossem eternos, dominados pela inautenticidade, o que é, por sua vez, fatal, posto que "a maneira como organizo minha vida sem dúvida depende de minha certeza quanto ao fato de que vou morrer em algum momento e de minha incerteza com relação à quando vou morrer" (INWOOD, 2004, p. 91).

Diante disso, não há dúvidas de que a experiência de Ivan está de acordo com o fato de que "o Dasein se atém, de início e na maior parte das vezes, a um ser-para-a-morte impróprio" (HEIDEGGER, 2005b, p. 43). Essa fuga fica ainda mais evidente na seguinte reflexão de Ivan:

Ivan llitch via que estava morrendo e desesperava-se. No fundo do coração sabia que estava indo embora e, longe de acostumar-se com a ideia, simplesmente não conseguia entendê-la. O exemplo de um silogismo que aprendera na Lógica de Kiezewetter, "Caio é um homem, os homens são mortais, logo
Caio é mortal", parecera-lhe a vida toda muito lógico e natural se aplicado a Caio, mas certamente não quando aplicado a ele próprio. Que Caio, ser abstrato, fosse mortal estava absolutamente correto, mas ele não era Caio, nem um ser abstrato. Não: havia sido a vida toda um ser único, especial. Fora o pequeno Vany a, com mamãe e papai e Mita e Volodya, com brinquedos e um tutor e uma babá; e mais tarde com Kátia e todas as alegrias e prazeres da infância, da adolescência e da juventude. O que sabia Caio do cheiro da bola de couro de que Vanya tanto gostava? Por acaso era Caio quem beijava a mão de sua mãe e escutava o suave barulho da seda de suas saias? Foi por acaso Caio quem se envolveu em protestos quando estudante de Direito? Foi Caio quem se apaixonou? Quem presidiu sessões como ele? E Caio certamente era mortal e era mais do que justo que morresse, mas ele, o pequeno Vanya, Ivan llitch, com todos os seus pensamentos e emoções, é completamente diferente. Não pode ser verdade, isto seria terrível demais. [...] Era assim que se sentia por dentro. "Se eu tinha que morrer, assim como Caio, deveriam ter-me avisado antes. Uma voz dentro de mim desde o início deveria ter-me dito que seria assim. Mas não havia nada em mim que indicasse isso; eu e todos os meus amigos sabíamos que no nosso caso seria diferente. E eis que agora... Não... não pode ser e no entanto é assim! Como entender isso?" (TOLSTÓI, 2007, p. 62-63).

Trata-se aqui de uma cena da novela bastante eloquente, evidenciando que Ivan está dilacerado. Do ponto de vista da analítica heideggeriana, essa reflexão de Ivan a partir do silogismo significa, com efeito, o ser-para-a-morte cotidiano e impessoal, no sentido em que

[...] num tal discurso, o ser-para-a-morte é compreendido como algo indeterminado, 
que deve surgir em algum lugar mas que, de início, para si mesmo, ainda-não é simplesmente dado, não constituindo, portanto, uma ameaça. $\mathrm{O}$ "morre-se" divulga a opinião de que a morte atinge, por assim dizer, o impessoal [...] mas eu não; pois o impessoal é o ninguém. [...] O Dasein adquire a capacidade de perder-se no impessoal, no tocante a um poder-ser privilegiado, que pertence ao seu ser mais próprio (HEIDEGGER, 2005b, p. 35).

Heidegger (2005b) argumenta, assim, que não basta ter apenas uma "mera certeza empírica" a respeito da morte. O pensamento sobre a morte, na realidade, precisa desentranhar na existência do ser o desvelamento da condição de possibilidade de autenticidade do modo de ser-no-mundo do Dasein, uma vez que a finitude é a marca mais distintiva do Dasein lançado no mundo. Por isso, a categoria ser-para-a-morte visa tratar o fenômeno da morte como iminente, de que o Dasein é um projeto finito, de maneira que "a morte é uma possibilidade ontológica que o próprio Dasein sempre tem de assumir" (HEIDEGGER, 2005b, p. 32).

Nesse aspecto, o filósofo alemão esclarece que "a morte é a possibilidade mais própria do Dasein. O ser para essa possibilidade abre ao Dasein o seu poder-ser mais próprio, em que sempre está em jogo o próprio ser do Dasein" (HEIDEGGER, 2005b, 47). Com essa acepção, a morte apenas pertence ao Dasein em sentido próprio, pois "reivindica o Dasein enquanto singularidade. A irremissibilidade da morte, compreendida na antecipação, singulariza o Dasein em si mesmo" (HEIDEGGER, 2005b, p. 47).

Justamente por esse funcionamento que Ivan ao se desesperar na iminência do falecimento, devido à doença, possui o seu Dasein singularizado, que a partir de uma torção radical, começa a analisar sua experiência de vida:

Ocorreu-lhe, pela primeira vez, o que the tinha parecido totalmente impossível antes - que ele não teria vivido como deveria. Veio-Ihe à cabeça a ideia de que aquela sua leve inclinação para lutar contra os valores das classes altas, aqueles impulsos de rebeldia que mal se notavam e que ele havia tão bem aplacado talvez fossem a única coisa verdadeira, e o resto todo, falso. E suas obrigações profissionais e a retidão de sua vida e sua família e sua vida social tudo falso e sem sentido. Tentou defender essas coisas a seus próprios olhos e subitamente deu-se conta da fragilidade do que estava defendendo. Não havia o que defender. "Mas se é assim", falou para si, "e se eu estou deixando essa vida consciente de que perdi tudo o que me foi dado e não há como remediar - então, qual o sentido?". Ficou deitado e começou a repassar toda sua vida mais uma vez [...] e viu claramente que estava tudo errado, uma horrível, monstruosa mentira camuflando vida e morte (TOLSTÓI, 2007, p. 94).

Ivan percebeu, assim, a nulidade de seu projeto existencial, o que lhe provoca raiva por toda a inautenticidade que o cercava, "essa falsidade em volta e até mesmo dentro dele" (TOLSTÓI, 2007, p. 74). Isso significa que a iminência da morte lhe trouxe questionamentos fundamentais acerca do seu modo de ser-no-mundo, fazendo-o perceber que, na realidade, sua situação "não é uma questão de apêndice ou rim, mas de vida... ou de morte" (TOLSTÓI, 2007, p. 59), no sentido em que deveria começar a encarar a finitude constitutiva do Dasein.

Com isso, surge para Ivan a culpa e a angústia.

De acordo com Giacóia Jr. (2013), o Dasein é resgatado para a autenticidade pela culpa, pois "a culpa é um faltar a si, é ser-em-falta; estar em dívida com as possibilidades de ser si-próprio" (GIACÓIA JR., 2013, p. 81). Percebendo a finitude, Ivan ouve o apela da voz da consciência da culpa e, assim, busca refletir o seu ser-no-mundo, examinando "as lembranças do passado" (TOLSTÓI, 2007, p. 90). Tal exame é fundamental para tornar-se autêntico, pois, do ponto de vista da analítica ontológica heideggeriana,

[...]o Dasein é sempre o seu passado e não apenas no sentido do passado que sempre 
arrasta "atrás" de si e, desse modo, possui, como propriedade simplesmente dadas, as experiências passadas que, às vezes, agem e influem sobre o Dasein. Não. O Dasein "é" o seu passado no modo de seu ser, o que significa, grosso modo, que ele sempre "acontece" a partir de seu futuro. Em cada um de seus modos de ser e, por conseguinte, também em sua compreensão do ser o Dasein sempre já nasceu e cresceu dentro de uma interpretação de si mesmo, herdado da tradição (HEIDEGGER, 2005a, p. 48).

Concomitante com o exame das lembranças do passado, surge para Ivan a angústia. Vale lembrar que, para Heidegger (2005b), a angústia é uma disposição de afeto fundamental para o Dasein, no sentido mesmo de que se trata de "um ânimo que abrange todas as possibilidades de ser do Dasein em sua raiz: a tensão entre ser-si-próprio e perder-se, desgarrar-se, a possibilidade sempre presente de faltar a si" (GIACÓIA JR., 2013, p. 76).

Nas palavras do filósofo alemão, a angústia traz à tona "o ser para poder-ser mais próprio, isto é, o ser livre para a liberdade do-a-si-mesmo se escolher e se-possuir" (HEIDEGGER, 2005b, p. 53).

De fato, a angústia colocou Ivan, enquanto Dasein, diante de uma possibilidade privilegiada, possibilitando-Ihe a compreensão de uma modificação existênciária no modo de ser e agir, com si mesmo e com os outros visando uma característica mais autêntica:

E ele começou a repassar em sua imaginação os melhores momentos de sua agradável vida. Mas, estranhamente, nenhum desses melhores momentos de sua vida tão agradável agora lhe pareciam o que pareceram na época. [...] Do período que produziu o atual Ivan llitch para cá tudo que parecera, na época, alegria, agora se desvanecia ante seus olhos e transformava-se em alguma coisa trivial e, em alguns casos, até repugnante. [...] Seu casamento... tão gratuito quanto o desencanto que se seguiu. E o mau hálito de sua esposa e os momentos de sensualidade e a hipocrisia! E aquela odiosa vida oficial e a preocupação com dinheiro. Um ano, dois anos, dez, vinte e sempre a mesma coisa. $E$ quanto mais o tempo passava, mais detestável ficava (TOLSTÓI, 2007, p. 87-88).

Ivan compreendeu a finitude ontológica e, assim, quando "procurou seu antigo medo da morte não o encontrou" (TOLSTÓI, 2007, p 99). Ou seja, Ivan compreendeu que é um ser-para-a-morte a partir da angústia que sentiu nos seus últimos meses de vida e, com isso, tencionou um modo de ser-no-mundo mais autêntico. Isso ocorreu porque "a disposição fundamental da angústia pertence à compreensão de si mesmo, próprio do Dasein. O ser-para-a-morte é, essencialmente, angústia" (HEIDEGGER, 2005b, p. 50).

Não obstante Ivan ter se visto diante de si-mesmo singularizado, com a intenção de reconfigurar o seu projeto existencial, a gravidade de sua doença o levou à óbito. Dessa maneira, ocorre que a biografia de Ivan llitch evidencia que foi um Dasein que não desenvolveu uma singularidade própria, percebendo tarde demais o caráter inautêntico e alienante de sua vida.

\section{Observação final}

Em A morte de Ivan Ilitch, o emprego do discurso indireto livre fez que o narrador não cedesse ao didatismo ao abordar as crises e reflexões de Ivan Ilitch acerca da nulidade de seu projeto existencial. Com isso, a forma realista de representar o modo inautêntico de ser-no-mundo desse personagem torna-se completamente corrosiva.

Ivan llitch vive dois momentos históricos: o início da cultura de negação da finitude e o aumento do aparato burocrático do Estado russo. Esses dois aspectos histórico-sociais estão intimamente relacionados à estrutura da obra, articulados pela lucidez e argúcia estética e crítica de Tolstói.

Em nossa interpretação hermenêutico-fenomenológica, pautada na analítica ontológica heideggeriana, visamos explicitar que as maneiras de ser e as maneiras de agir do personagem Ivan llitch são o 
correspondente ôntico da condição de decaimento [Verfallenheit] do Dasein em uma cotidianidade intramundana na qual se oblitera as possibilidades mais autênticas de ser-si-próprio.

A categoria ser-para-a-morte foi fundamental para compreendermos que a inautenticidade de Ivan é, com efeito, uma fuga decadente da finitude e de si mesmo. Também que seu processo de adoecimento possibilita compreender o irremediável ser-para-a-morte do Dasein, iniciando, assim, todo um processo de reflexões acerca de sua falta com relação ao seu poder-ser mais autêntico. Esperamos, assim, ter demonstrado que finitude e autenticidade são duas instâncias discursivas articuladas organicamente, ao longo da perspectivação dos acontecimentos diegéticos, promovendo a atualidade e utilidade de sua crítica social corrosiva à atual interdição da morte (ARIÈS, 2012) e ao império puramente pragmático do agir instrumental, ao imputá-los como produtores de uma sociedade desumanizada.

\section{Referências}

ARIÈS, Philippe. História da morte no Ocidente: da Idade Média aos nossos dias. Tradução Priscila Viana de Siqueira. Rio de Janeiro: Nova Fronteira, 2012.

BEZERRA, Paulo. Alienação a auto-imolação em A morte de Ivan llitch. Fragmentos, Florianópolis, v. 21, n. 1, p. 137-149, jan./jun. 2010.

BRYAN, Newton Antonio Paciulli. Rússia, século XIX: burocracia, modernização conservadora e emancipação dos servos. In: BRYAN, Newton Antonio Paciulli. Educação, trabalho e tecnologia. Campinas: Alínea, 2015. p. 108-159.

CANDIDO, Antonio. Literatura de dois gumes. In: CANDIDO, Antonio. A educação pela noite. Rio de Janeiro: Ouro Sobre Azul, 2006. p. 199-221.

GIACÓIA JR., Oswaldo. Heidegger urgente: introdução a um novo pensar. São Paulo: Três Estrelas, 2013.

HAUSER, Arnold. O romance social na Inglaterra e na Rússia. In: HAUSER, Arnold. História social da arte e da literatura. Tradução Álvaro Cabral. São Paulo: Martins Fontes, 1998. p. 831-887.
HEIDEGGER, Martin. O conceito de tempo. Tradução Irene Borges Duarte. 2. ed. Lisboa: Fim de século, 2008.

HEIDEGGER, Martin. Ser e tempo. Tradução Márcia

Sá Cavalcante Schuback. 15. ed. Petrópolis: Vozes, 2005a. pt. 1.

HEIDEGGER, Martin. Ser e tempo. Tradução Márcia Sá Cavalcante Schuback. 13. ed. Petrópolis: Vozes, 2005b. pt. 2.

INWOOD, Michael. Heidegger. Tradução Adail Ubjrajara Sobral. São Paulo: Loyola, 2004.

LUKÁCS, Georg. Tolstói y la evolución del realismo. In: LUKÁCS, Georg. Ensayos sobre el realismo. Tradução Juan Jose Sebrelli. Buenos Aires: Siglo Veinte, 1965. p. $163-263$.

REALE, Giovanni. Martin Heidegger: da fenomenologia ao existencialismo. In: REALE, Giovanni. História da filosofia: do romantismo até nossos dias. Tradução Álvaro Cunha. 2. ed. São Paulo: Paulus, 1991. p. 581592.

RICOEUR, Paul. Função hermenêutica do distanciamento. In: RICOEUR, Paul. Interpretação e ideologias. Tradução Hilton Japiassú. 4. ed. Rio de Janeiro: F. Alves, 1990. p. 43-57.

TOLSTÓI, Leon. A morte de Ivan Ilitch. Tradução Vera Karam. Porto Alegre: L\&PM, 2007.

RECEBIDO EM: 30/01/2019

ACEITO EM: 24/07/2019 